meshwork of extra junior doctors between themselves and the patient.

Some of the emphasis has now shifted to the senior registrar grade with the setting up of the Joint Planning Advisory Committee. There is a danger that this initiative will, like the Platt report, divert attention from the fundamental problems that have always been at the senior house officer and registrar stage. The real priority at senior registrar level is to recognise that consultant expansion, if it is to occur on a substantial scale, needs more senior registrars to fuel it-not for ever, but while the expansion is in progress.

If this is the way we intend to go most of our problems could be solved by converting a substantial number of registrar posts into senior registrar posts. But this would really force the issue. Districts would need to find the money for consultant expansion; consultants would need to accept its implications, with existing or somewhat reduced levels of junior staffing; and the fear of producing time expired or unemployed senior registrars would be a dread deterrent.

\section{Need for short term strategies}

We have prevaricated so long over postgraduate training and hospital medical staffing that time really has run out. What we need to do now is think of some short term strategies that will keep a show on the road while holding open the long term options. We should be talking with managers about accountability as the price of our independent professional judgment. Clinical freedom without corporate responsibility may happily be dead; long live clinical leadership, both in policy discussion and in its implementation.

James Johnson is right that we should think the unthinkable and seriously discuss a subconsultant grade. ${ }^{6}$ We cannot too lightly discard the idea of more than one consultant or specialist grade as being impracticable. Up and down movement within the top bracket might be a sensible variant on the time limited contract that Alan Maynard and others have seriously proposed.' Also, we should recognise that a system as complex and elastic as the NHS needs a few cushions-well fashioned and not just hiding shoddiness under cheap embroidery. Altogether, there is a lot more talking to do and it has to be done quickly. To restore the morale of the service and get away from the awful disenchantment with hospital careers that so many young doctors have we need something better than a panic response to a self induced crisis.

1 Social Services Committee. Fourth report from the social services committee 1980-81: medical education with special reference to the number of doctors and the career structure in hospitals. London HMSO, 1981. (HC 31-I)

2 Woodyard JE. Orthopaedic iunior staff. Br Med f 1986;292:902.

3 Woodyard J. The doctors' malaise that threatens our good health. Guardian 1986 March 24:13 (col 2).

4 Perry FS. Cold comfort in the NHS. Guardian 1986 March 31:10 (col 2)

5 Higham JH. Cold comfort in the NHS. Guardian 1986 March 31:10 (col 2)

6 Johnson JN. Cycle of gloom over manpower. Br Med F 1985;291:361-2.

Maynard A. The nonsense of doctors' contracts. Health and Social Services fournal 1985 Dec 19-26:1610.

(Accepted 8 April 1986)

\title{
Bed numbers and good medical education
}

\author{
IAIN E GILLESPIE, DONALD LONGSON
}

One of the decisions being implemented throughout the National Health Service is to reduce the number of acute general surgical and medical beds. The various regional health authorities argue that such reductions will be compatible with meeting their service commitments but have taken less notice of the implications of such changes for teaching.

In teaching hospitals the cutback in these beds is exacerbated by the expansion of highly specialised regional services that encroach on the dwindling pool of beds available to general services and emergencies. Most of these expanding specialties operate in relative clinical isolation or collaborate with other departments for clearly specified needs. There are many reasons why they make a limited, though useful contribution to undergraduate medical education, especially in its early phase. It is against this background that clinical teaching must survive and yet it receives little attention in the current medicopolitical maelstrom. It is tacitly assumed that education is infinitely adaptable and that its requirements can be met by conscience money, square metres of teaching space, and the funding by the NHS of posts in the university-even if these posts are in subjects of small curricular importance. This is a lamentable underestimation of the needs of clinical medical education.

The dispersal of students to district general hospitals is an excellent educational innovation. Students return from these clerkships with enhanced confidence and maturity; they have had

\section{University of Manchester, Manchester M13 9PT}

IAIN E GILLESPIE, MD, FRCS, dean of the medical school

DONALD LONGSON, MB, FRCP, chairman, board of the faculty of medicine

Correspondence to: Professor Gillespie, University of Manchester, Stopford Building, Oxford Road, Manchester M13 9PT. closer contact with patients than is possible in the teaching hospital; in many instances they have had excellent teaching. But, in general, they have been falsely credited with competence in basic clinical methods and their performance has not been systematically checked and corrected. Our enthusiasm for this type of experience is unfeigned and we would not wish to revert to the old system. It does not follow, however, that we view external clerkships as a possible substitute for training in the teaching hospital; they are complementary to it. There is an undiminished need for early education to take place in an educational establishment with its discipline and curricular overview. For instance, the success of the external clerkships depends greatly on the training in basic clinical method inculcated in the early part of the clinical course, and the teaching of clinical method is the first casualty when the inpatient services are curtailed; perhaps our policy makers ought to be better informed about the matter.

\section{Fear of clinical uselessness}

"Clinical method" includes all the tools that the doctor employs when confronting a patient. It includes the verbal skills necessary to explore the patient's subjective experiences and his circumstances in life, the sensory skills for the doctor to observe malfunctions and distortions of anatomy, and the verbal skills of explanation and advice. Without "clinical method" even the polymath is reduced to clinical uselessness. These skills increase in effectiveness and range throughout professional life but a minimum package is necessary before the student can start to role play and benefit from exposure to specialties where there are already complaints of deficient clinical skills. The clinical tyro must surmount great obstacles: many social, psychological, and even sexual inhibitions must be overcome; a higher degree of articulateness is required than many young people possess and it is against this delicate background that, often for the 


\section{Public health inquiry}

After the publication of the report on the outbreak of food poisoning at Stanley Royd Hospital the Secretary of State set up an inquiry into the future development of the public health function and community medicine in England. The membership of the inquiry was published on 22 March ( $p$ 838).

The terms of reference are: "To consider the future development of the public health function, including the control of communicable diseases and the specialty of community medicine, following the introduction of general management into the hospital and community health services, and recognising a continued need for improvements in effectiveness and efficiency; and to make recommendations as soon as possible, and no later than December 1986."

In inviting the BMA to submit evidence the secretary to the inquiry has suggested that the association might wish to bear in mind the following points:

"The task of the inquiry, as described by the Secretary of State when he announced its establishment on 21 January, is to undertake 'a broad and fundamental examination of the role of public health doctors, including how such a role could best be fulfilled.'

"As a working list of the areas in which the specialist in community medicine has responsibilities, the committee has taken the following: determining the health needs of whole populations; contributing to planning of appropriate health services, and evaluating the outcome of such services; ensuring that health authorities are provided with medical advice of appropriate quality as and when necessary; control of communicable disease (including 'proper officer' functions); medical advice and support to local authorities in connection with their other environmental health functions and their social services and housing functions; health surveillance of preschool and school age children and advice and support to local education authorities in connection with various statutory functions; prevention, health promotion, and health education; provision, coordination, and evaluation of programmes which require coordination of the work of doctors both within and outside hospitals - for example, immunisation, screening programmes.

"The committee's work will include an examination of recruitment and training in community medicine.

"The committee would find it very helpful if written evidence submitted to it could be structured to cover the following particular points: comments on the committee's working list of areas of responsibility of community medicine specialists... how effectively the responsibilities in that area are discharged at present; what problems are perceived (if any); and, where appropriate, what solutions, within the committee's remit, can be identified."

Written evidence has been requested by 11 July.

\section{CCCMCH to prepare evidence for Acheson inquiry}

The Central Committee for Community Medicine and Community Health held its Spring meeting on 25 April 1986. Dr David Miles was in the chair. One of the main items considered was the
Department of Health and Social Security's invitation to the BMA to submit evidence to the Acheson inquiry into the future development of the public health function, including the control of infectious diseases and the specialty of community medicine, in England. A working party has been set up to draft evidence from the committee which will report back to the meeting of the committee scheduled for June, just before the annual conference of community medicine and community health.

The committee was disappointed to hear that the child health forum, set up at the request of the annual representative meeting, had not made the progress that had been hoped in resolving the differences between the various bodies negotiating for the continuation and improvement of the child health service. The committee was told that an interim report from the forum would be made to the May council meeting.

Two important documents- "Primary Health Care-An Agenda for Discussion" and "Neighbourhood Nursing-A Focus for Care" arrived just in time to appear on the committee's agenda. These have been referred for detailed consideration in the executive with a view to ensuring that the committee's views are incorporated with those from other interested crafts in the BMA's response to the DHSS

The committee also discussed the new arrangements for recommending the names of community physicians for $\mathrm{C}$ distinction awards. Recommendations for community physicians as well as clinicians will now be considered by the regional awards committees, which will select the names of those to be recommended to the central advisory committee on distinction awards. The CCCMCH has suggested that it would be helpful to invite the chairman of that committee to attend one of its meetings next session, when the new arrangements for putting forward names has been in operation for a year.

\section{Bed numbers and good medical education (continued)}

first time in their lives, they are expected to develop skills by their own efforts, the teacher's influence being merely that of an adviser and guide and not a purveyor of information. The fact that they must perform in public is another source of stress.

The teaching of "clinical method" cannot be combined with the delivery of care to the patient either in the wards, outpatient clinics, district hospitals, or general practice. Although performed with patients and in clinical areas, it is, in fact, a classroom exercise during which some aspects of the case (normal or abnormal) are selected for discussion and examination. For instance, if the students are being intelligently led into the complexities of the hypotheticodeductive method it may take an hour or more to unravel a small part of a patient's history. For the development of examination skills the various manoeuvres must be diligently and repeatedly performed by each student in the group, and this teaching is totally frustrated if the students do not practise on the patients between the formal classes. Most patients are outstandingly cooperative and long suffering, but it is clearly our duty to spread the ordeal as thinly as possible and yet expose the students to a reasonably wide selection of human miseries. The importance of the patient-student ratio is plain for all to see and the General Medical Council recommendations are hardly excessive since some patients are unsuitable, and the longer stay patients soon exhaust their teaching potential. The difficulties in providing this form of teaching increase as the pool of suitable patients decreases and there are many reasons why patients in particular specialties are unsuitable. Furthermore, we contend that this kind of teaching demands from the teacher a special disposition of mind, the willingness and time to be patient, and a reflective attitude. This is not covert élitism.

\section{Distorting medical training}

So far we have described features that are or should be widely known. There is another difficulty that is not immediately obvious. As the pressure on beds increases the threshold for admission is necessarily raised until, effectively, only acutely ill patients are admitted. This grossly restricts the range of problems which students see. Patients with complex cold, organic problems are more likely to be hidden from their view at a formative moment in their career. These patients and those with psychosomatic problems call for aspects of clinical method which are not necessarily relevant or even present in emergency admissions, the majority of whom are afflicted by one of a fairly narrow range of diseases. We are faced by a dangerous distortion in medical training at a time when there is already concern about the clinical skill evident at graduation. Arguments can also be developed about the supply of patients in the run up to the final examinations, when the accumulated knowledge needs to be integrated under the watchful eye of those responsible for standards and examination. Unfortunately, the matters which concern us here do not appear in computer printouts but unless corrected they will surely appear in quality of care balance sheets in years to come.

We are not unsympathetic to the need for efficiency but the ever increasing speed of turnover means that some students never have the opportunity of spending time with their patients_or even see them. But the changing threshold for admission and the restrictions of numbers of beds seem to be profoundly inimical to good medical education and we suspect that many will share our concern.

(Accepted 7 April 1986) 